\title{
Adult Learning Across USA, Canada, and New Zealand: A Cross-Cultural Study of PIAAC
}

\author{
Chong Ho Yu ${ }^{1}$, Hyun Seo Lee ${ }^{1}$, Emily Lara ${ }^{1} \&$ Siyan $\mathrm{Gan}^{2}$ \\ ${ }^{1}$ Department of Psychology, Azusa Pacific University, California, USA \\ ${ }^{2}$ Graduate School of Education and Psychology, Pepperdine University, California, USA \\ Correspondence: Chong Ho Yu, Department of Psychology, Azusa Pacific University, Azusa, CA 91702, USA. \\ Tel: 1-480-567-4782. E-mail: chonghoyu@gmail.com
}

\author{
Received: October 2, 2018 \\ Accepted: December 19, 2018 \\ Online Published: April 29, 2019 \\ doi:10.5539/ies.v12n5p1 \\ URL: https://doi.org/10.5539/ies.v12n5p1
}

\begin{abstract}
Skeptics of Programme for International Student Assessment (PISA) and Trend for International Math and Science Study (TIMSS) argue that while US elementary and high school students are behind their peers in other nations, the US workforce is still excellent because of the high quality post-secondary educational institutions in the US. However, the Programme for the International Assessment of Adult Competencies (PIAAC) indicates that US adults are in fact far behind their international peers in literacy, numeracy, and technology-based problem solving. Through the use of data mining, this study explored the possible association between PIAAC scores and several constructs. Since the US, Canada, and New Zealand were considered culturally similar nations, according to cluster analysis, patterns between PIAAC scores and selected constructs were analyzed by a variety of big data analytical methods, including cluster analysis, bootstrap forest, boosted tree, and data visualization. Given that PIAAC used multiple computerized adaptive testing, the consequential plausible values were randomly selected when the ensemble approach was used. Additionally, model comparison was utilized to decide between bagging and boosting in order to select the optimal model for each sample. In these samples, cultural engagement, readiness to learn, and social trust, respectively emerged as strong predictors for learning outcomes as they were assessed by PIAAC.
\end{abstract}

Keywords: adult learning, archival research, cross-cultural comparison, international assessment, social trust, readiness to learn

\section{Introduction}

\subsection{Introduce the Problem}

This research project utilizes data mining techniques, including cluster analysis, bootstrap forest, boosted tree, and data visualization, to identify patterns in an archival data set consisting of 127,757 observations across 18 countries. This study helps to assess where the US stands in comparison to its national counterparts and to provide insight into the direction of the country. By taking advantage of globalization, we aim to incorporate useful strategies from other countries to promote educational improvement within the US. In a world of increasingly global competition, many nations devote tremendous efforts to improve the education and skill level of their citizens. Skeptics of international assessments argue that while the US grade school and high school students are behind their peers in other nations, the US workforce is still excellent because of the high quality post-secondary educational institutions in the US (Ravitch, 2011). However, Programme for the International Assessment of Adult Competencies (PIAAC) conducted by Organization for Economic and Cooperation and Development (OECD) indicates that not only American students, but also American adults are far behind their international peers in all three test categories: literacy, numeracy, and problem-solving in technology-rich environments.

\subsection{Explore Importance of the Problem}

Established in 1961, OECD is a global organization that facilitates international conversation and provides resources regarding pressing issues that nations across the world face. OECD's primary concern is to create policies that promote positive global change. In order to facilitate this, OECD has established a foundation on international data collection, including PIAAC, whch is an extension of Programme for International Student Assessment (PISA). The primary difference between the two assessments is the target population. PIAAC assesses 
adults, whereas PISA assesses 15-year old students. PIAAC research is sponsored by the U.S. Department of Education's National Center for Education Statistics (NCES, 2016) and has been used to evaluate both the global trends regarding adult learning, as well as the US's current status of adult learning in comparison to those global trends (Linton, 2010).

OECD conducted two rounds of data collection. Round 1 data were collected from 24 countries between 2011 and 2012. The round 1 report was released in 2013, showing that young Americans aged from 16 to 24 had the lowest score in numeracy and problem-solving in technology-rich environments, and were ranked 17 th in literacy. When all age groups were combined, the US sample ranked 16th in literacy, 21st in numeracy, and 14th in problem-solving (OECD, 2013c). Nine additional countries participated in the second round of data collection between 2014 and 2015, and OECD released the report in 2016 (OECD, 2016). After combining the data from the other nine countries to the analysis, the US ranked 18th in literacy, 27th in numeracy, and 16th in problem-solving. These consistently low scores by US participants are indeed concerning. Certain findings are even more alarming. For example, the younger generation of Singaporeans (aged 16-24) outperformed the older generation (aged 55-64) in literacy, but this trend is reversed in the US. In the US, the younger generation fell behind the older, indicating Americans of former generations had better literacy skill than younger Americans. However, literacy is not the only skill in which this pattern is found within this data set. A similar pattern can also be found in technology-based problem-solving. Many older Americans successfully reached Level 2 and 3 in problem-solving skill level, placing the US as the second to the highest performer for this skill. Yet, the problem-solving skill of young Americans was among the bottom six.

Washington Post writer, Zakaria (2014), responded to the Round 1 report by expressing his concern that there is a wide disparity between the best performers and worst performers in the US. From Zakaria's perspective, PIAAC and PISA results are consistent because both tests indicate that American learners are falling behind their international peers, implying that a poor educational foundation has the tendency to place individuals in a vulnerable situation because significant stressors are more likely to persist throughout their lives. In this sense, regardless of being the lead in best colleges or universities around the world, it is unlikely that the US will be able to save its adolescents and adults with simply having higher quality post-secondary education.

While simply modeling US education after top performers of PIAAC in education, such as Japan and Finland, seems like a possible way to rectify the issue, there are factors that may complicate this procedure. When considering culture differences, some professionals argue that instead of making positive changes, such variances can make the implementation an unsuccessful one (e.g. Menon, 2000). To address this concern of cultural incompatibility, the authors of this paper utilized hierarchical cluster analysis to treat the variables that reflect cultural norms from the PIAAC data set. The objective of the cluster analysis is to determine which countries are culturally similar to the US in terms of shared patterns of learning behaviors, attitudes toward social trust, cultural engagement, and political efficacy. The cluster analysis showed that the US, Canada, and New Zealand were similar to each other in the preceding cultural traits. Next, bootstrap forests and boosted trees were generated to investigate how these cultural traits influence learning outcomes. Model comparison was then utilized to select the best model. From these analyses, three variables were identified as strong predictors of learning outcomes: cultural engagement, readiness to learn, and social trust. Within the New Zealand sample, which scored the highest in this group, social trust was found to be the strongest predictor relating to the composite PIAAC scores.

\subsection{Relevant Scholarship}

\subsubsection{Human Capital Approach vs. Humanistic Approach}

PIAAC was developed to assess the national value of a nation's human capital or the competencies of their adult citizens by focusing on the measurement of knowledge, cognitive, and technical skills that are broadly transferable (OECD, 2013c). In a general sense, human capital is defined as the "social return from investment in people's attainment of qualifications" (Tsatsaroni \& Evans, 2014, p. 173). From an economic standpoint, PIAAC contains human capital data of countries that were unavailable in the past. By gathering such information, the shortcomings of a nation become more visible, which gives the nation's government an opportunity to address the issues directly. With this new information, countries are also able to see its competition of human capital in other countries. Thus, while there are arguments regarding how human capital should be used (Tsatsaroni \& Evans, 2014), in an economic sense, PIAAC has the potential to be incredibly useful for guiding education policies.

While the use of human capital data could offer insight for policymakers, the assessment framework based on the human capital approach is not without controversy. Tsatsaroni and Evans (2014) criticize that the idea of human capital is economically-driven. This contradicts a humanistic approach, which emphasizes the intrinsic motivations of learning. While this is indeed a concern, the questions found in PIAAC surveys are practical, in that 
they address activities that are necessary for individuals to perform daily. For example, in the literacy portion of the survey, participants are given a scenario about taking their children to school. They are asked to answer the question, "what is the latest time that children should arrive at preschool" (National Center for Education Statistics [NCES], 2016). There are many programmatic questions like this found in the PIAAC quiz bank. Thus, scholars should not dismiss the ability of PIAAC to measure the basic skills of an adult. At the same time, it is also crucial to view human capital and the humanistic approach as entities that have different purposes.

\subsubsection{Global Competition and Cross-Cultural Comparison}

With the rise of globalization, nations have found that to succeed, they must both compete and cooperate with each other (Ananiadou \& Claro, 2009; Bagley \& Portnoi, 2014; Held \& McGrew, 2007). At times, this interaction creates concern for the US due to its position in the larger global community. However, the idea of the knowledge economy, which refers to the increasing supply and demand of knowledge of technological advances, arose as a new arena of global competition (Brown, Green, \& Lauder, 2001; Gonzales, Jones, \& Ruiz, 2014). How compatible the knowledge and skills of the workforce are with the knowledge economies determines the competitiveness of, not only an individual but of a nation. In the past, America's low-skilled workers had little concern with looking for jobs because there was vast job availability in markets like transportation, manufacturing, and retail.

Since the beginning of the twenty-first century, many Asian countries have experienced growing popularity in the manufacturing industry. Because of this shift, it is predicted that many of America's low-skilled workers will lose their jobs (Crotty, 2015). At the same time, with the advancement of technology, more low-skilled workers will continue to become unemployed (Meyerson, 2014). Technology will only become more advanced and require more skilled workers to perform different and complex tasks. This trajectory thus creates a vicious cycle for those who are equipped with lower-skills. In the context of global competition, PIAAC provides participating nations with reference to their relative standing in the global marketplace.

However, the role of culture in these global assessments must be considered. In response to PISA, which assesses 15-year-old students, Furedi (2013) argued that what constitutes effectiveness in education is tied to cultural and social contexts. Whether or not students can build a passion for learning is strongly shaped by the cultural norms in their communities. The cultural variation must be addressed when analyzing the traits of different nations (Moran, Abramson, \& Moran, 2014). This is especially significant when the topic is learning. Culture significantly influences the cognitive process of obtaining, organizing, and processing information (Aktaş, 2012; De Vita, 2001; Holtbrügge \& Mohr, 2010; Joy \& Kolb, 2009; Moran et al., 2014; Sternberg \& Grigorenko, 2004; Yamazaki, 2005). For instance, individuals in the US tend to believe that only certain people have the potential and capacity to become highly intelligent. In contrast, in South Asian Indian settings, it is assumed that most people are able to become highly intelligent if they strive to achieve higher knowledge (Rattan, Savani, Naidu, \& Dweck, 2012). Thus, it is difficult to generate practical implications for education when the assumptions of learning differ between cultures. Hence, this study only compared nations that are culturally similar.

\subsubsection{Learning Outcomes and Contributing Factors}

In PIAAC, three skill domains are assessed: literacy, numeracy, and technology-based problem-solving. Literacy is defined as "understanding, evaluating, using and engaging with written text to participate in society, to achieve one's goals and to develop one's knowledge and potential," (OECD, 2012, p. 20). Whereas numeracy is defined as "the ability to access, use, interpret, and communicate mathematical information and ideas, to engage in and manage mathematical demands of a range of situations in adult life" (p. 33). PIAAC defines problem-solving in technology-rich environments as "using digital technology, communication tools, and networks to acquire and evaluate information, communicate with others, and perform practical tasks" (p. 47).

When comparing PIAAC to the existing adult literacy surveys, such as the Adult Literacy and Life-skills Survey (ALL) and the International Adult Literacy Survey (IALS), PIAAC has advanced those surveys by combining prose and document literacy from ALL and IALS into a single domain of literacy, along with making adjustments to the definition of proficiency levels (OECD, 2013c). To accommodate this technology-rich society, numeracy is indispensable when individuals face a wide range of quantitative and mathematical information in their daily lives and work environments. Additionally, PIAAC has incorporated a new component of "problem-solving" to measure people's ability to find solutions to complex communication and information-based matters through technology (Hanushek, Schwerdt, Wiederhold, \& Woessmann, 2013).

In addition to test items about literacy, numeracy, and problem-solving in technology-rich environments, PIAAC includes many survey items related to learning. Based on the following review of literature, this study focused on certain cultural traits that might impact learning outcomes, namely, readiness to learn, cultural engagement, 
political efficacy, and social trust.

\subsubsection{Readiness to Learn}

The quality of motivation is closely related to the performance of the individual (Cerasoli et al., 2014). This present study seeks to capture the essence of motivation for learning and its impact on learning outcomes. While PISA offers a motivational psychological construct, namely Motivation to Learn (MtL), PIAAC, on the other hand, lacks an explicit measurement for motivation; instead, it consists of questionnaires related to psychometric factors for skill acquisitions, which refers to Readiness to Learn (RtL) (Gorges, Maehler, Koch, \& Offerhaus, 2016). Readiness to Learn is defined as the tendency to learn new things, relate information to prior knowledge and life situations, as well as engage in problem-solving and information-seeking behaviors. The construct of readiness to learn assesses non-cognitive skills, which involve factors that are not intellectual or metacognitive, such as self-regulation and time management (Smith et al., 2015). These factors recently have received recognition as important agents that promote an individual's attainment of skills and success (Heckman \& Kautz, 2013). Although RtL items in PIAAC do not seem to be candid indicators of motivation and/or educational participation and may vary in terms of core values, they are skills and behaviors that are relevant to learning (Smith et al., 2015). An individual's level of RtL may be able to measure whether the learner shows interest in the learning, as well as the drive to initiate, continue, and complete the learning task.

\subsubsection{Political Efficacy}

Another construct addressed in this research is political efficacy or an individual's sense of belief in one's willingness and ability to influence governmental authorities, institutions, and general political processes (da Costa, Rodrigues, Vera-Toscano, \& Weber, 2014). It acts as one of the indicators for the quality of democratic government, which shows whether the government is responsive to its citizens' opinions (Bowler \& Donovan, 2002). Thus, political efficacy also holds the value of "belief in one's own competence to understand and to participate effectively in politics," which is referred to as internal efficacy (Anderson, 2010). In PIAAC, the questionnaire for political efficacy asks its participants to respond to the statement "People like me don't have any say about what the government does," which was intended to measure an adult's internal political efficacy or their perspectives on whether they can have an impact on the political structure.

Studies have argued that education is, directly and indirectly, related to an individual's belief in his or her competencies (Bowler \& Donovan, 2002; Hayes \& Bean, 1993; Pasek, Feldman, Romer, \& Jamieson, 2008). Some reported that individuals with high educational levels tend to show higher levels of political efficacy than those with lower education levels (Hayes \& Bean, 1993). Others proposed a strong interaction between educational attainment and political participation with the assumption that educated people are more likely to acknowledge the importance of political awareness and involvement, and are more equipped with financial means for political engagement (Brady, Verba, \& Schlozman, 1995). The reviewed literature that used respondents' educational level as a proxy for political sophistication is largely confined to measuring the quantity of education, not the quality of education. Compared to the quantity of education, the quality of education is more closely related to learning competencies in literacy, numeracy, and problem-solving, which are variables assessed by PIAAC (da Costa et al., 2014). This present study may determine whether a relationship exists between political efficacy and PIAAC outcomes.

\subsubsection{Cultural Engagement}

Cultural engagement, also known as community engagement or citizen engagement, refers to the activities that build ongoing relationships for the benefit of both the individual and the community. This type of engagement is expressed in different forms, such as participation in artistic or intellectual activities. Prior research discovered that citizen engagement increased personal life satisfaction and happiness, improved physical and mental health, expanded social networks, and built more resilient and vibrant local communities and larger societies (Rudd, 2015). In PIAAC, the concept of cultural engagement is determined by the community volunteering in which someone has participated. One factor that may influence someone's community engagement is their level of education. In other studies, education has been found to have a strong association with volunteering (Wilson, 2000). Individuals with more formal education tend to have a heightened awareness of their civil duties and are better equipped to address social issues. They have greater understanding and empathy as well as an increased sense of self-confidence. While education may be, in some cases, a predictor of volunteer involvement, the relationship between these two variables could be bi-directional.

\subsubsection{Social Trust}

There are two questions related to social trust in the PIAAC survey. While society is often perceived as a whole 
unit, the direct interpersonal relationships taking place are important building blocks of the system. Before discussing the construct of social trust, it is important to first understand the definition of interpersonal trust, which involves one's willingness to take personal risks with the expectation that other's behaviors will accept and not abuse the risk that was taken (Borum, 2010). In other words, trusting others requires acceptance of the unpredictable nature of humanity, and the possibility of being mistreated by others. In the case of learning, research indicates that trust is a crucial factor in promoting knowledge sharing (Abrams, Cross, Lesser, \& Levin, 2003). Two aspects of trust that determine learning outcomes are identified as benevolence and competence. Benevolence is characterized by the idea of caring for one's overall well-being, while competence focuses on one's expertise on which other people can depend (Abrams et al., 2003). Thus, learning becomes a two-way process in which one party is required to be vulnerable, and the other to be genuine in caring as well as qualified enough to provide meaningful feedback.

\section{Method}

\subsection{Data Source}

Because PIAAC is an openly accessible database and the authors did not have any direct contact with human subjects, ethical approval by the institution review board (IRB) was exempted. Although 33 countries participated in PIAAC, only 18 developed countries were included in this study: Austria, Canada, Denmark, Finland, France, Germany, Ireland, Italy, Japan, Korea, Netherlands, Norway, Spain, Sweden, United States, Israel, New Zealand, and Singapore. The excluded nations were Australia, Chile, Greece, Indonesia, Lithuania, Slovenia, Turkey, United Kingdom, Poland, Russian Federation, Slovak Republic, Belgium, Czech Republic, and Estonia.

Most nations on the preceding list are the least developed countries. Australia, UK, Belgium, and Russia are considered developed countries, but they were excluded from this study for the following reasons. First, the data set of Australia is not publicly available. In addition, only one region (Flanders) was sampled from Belgium and two religions (England and Northern Ireland) were sampled from the UK. Needless to say, these two samples were not representative. The sample for Russia lacked the population of Moscow, the capital of Russia, and therefore the sample representativeness was also in doubt (OECD, 2013b).

\subsection{Variables}

The learning outcomes recorded in PIAAC were literacy, numeracy, and technology-based problem-solving scores. It is important to point out that OECD employed multiple computerized adaptive testing (MCAT) in PIAAC. In traditional computerized adaptive testing (CAT), the next question presented to the examinee depends on his or her response to the previous question. In MCAT, items are grouped into several clusters known as testlets. Similar to CAT, the next testlet seen by the examinee is dependent upon his or her performance on the previous testlet. Because not every PIAAC participant answered the same questions, OECD utilized imputation methods to estimate the scores. Uncertainty is an inherent property of any estimation and thus for every participant, OECD reported ten plausible scores, known as plausible values (PV) (OECD, 2013b). These plausible values represent the estimated distribution for a student's $\theta$ (student ability). According to $\mathrm{Wu}$ (2004), each PV is equally good for estimating the population characteristics, as each set forms a sampling distribution of the estimated student ability. Following the advice of Wu, this study used a randomly selected PV for literacy, numeracy, and problem-solving.

The scores of these three domains are significantly correlated (Table 1). As the sample size is extremely large, the $p$ value is more likely to be significant. Nonetheless, the ellipsoids in the scatterplot matrix (Figure 1) suggest that these three skills were strongly associated. Additionally, a principal component analysis indicated that if all three skills are combined into one component, the eigenvalue is as high as 2.5 and 83.55 percent of the variable is accounted for. By taking all of the above into consideration, the composite score of literacy, numeracy, and problem-solving was treated as the dependent variable or the overall learning outcomes.

Table 1. Correlation coefficients of literacy, numeracy, and problem-solving

\begin{tabular}{lcccccc}
\hline Variable & by Variable & Correlation & $n$ & Lower 95\% & Upper 95\% & $p$ \\
\hline Numeracy & Literacy & 0.8245 & 126324 & 0.8227 & 0.8262 & $<.0001^{*}$ \\
Problem-solving & Literacy & 0.7414 & 86115 & 0.7383 & 0.7444 & $<.0001^{*}$ \\
Problem-solving & Numeracy & 0.6920 & 86115 & 0.6885 & 0.6954 & $<.0001^{*}$ \\
\hline
\end{tabular}

Note. Significant at .01 level. 


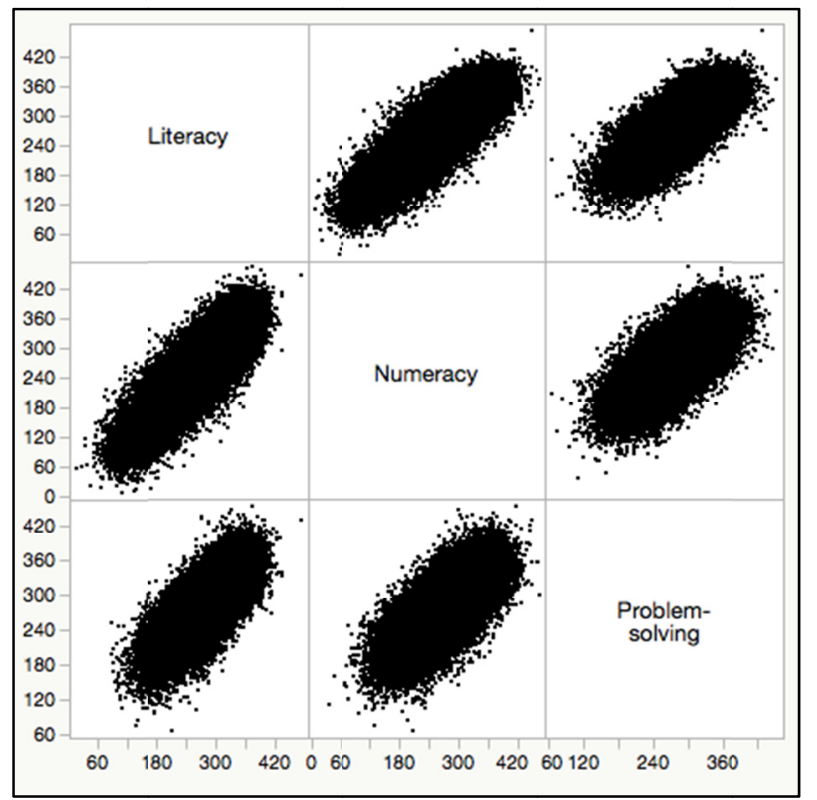

Figure 1. Correlation matrix of literacy, numeracy, and problem-solving

\subsection{Data Analysis}

Because OECD utilized multi-stage sampling, sample weights were used in all analyses. First, hierarchical clustering was employed to identify which countries are similar to the US regarding readiness to learn, cultural engagement, political efficacy, and social trust. Afterwards, two ensemble methods, the bootstrap forest and the boosted tree, were run with the subsets identified by hierarchical clustering. The rationale for choosing the ensemble approach over traditional regression analysis is simple: numerous studies have confirmed that the ensemble approach outperforms any single classifier (Dietterich, 2000; Meir \& Ratsch, 2003).

Bagging and boosting are the two most popular ensemble methods. Both methods are based on machine learning, in which data sets are partitioned and analyzed by different models. Each model is considered a weak learner and the final solution is a synthesis of all these weak learners. Both are also resampling methods because the large sample is partitioned and re-used in a strategic fashion. When different models are generated by resampling, inevitably some are high bias models (underfit) while some are high variance models (overfit). In the end, the ensemble cancels out these errors. In addition, it can also account for sample variation. Specifically, each model carries a certain degree of sampling bias, but in the end, the errors cancel out each other and the most crucial predictors are ranked by the sum of squares (Wujek, 2016).

It is with the authors' confidence that there is no single best ensemble method for all situations. An appropriate strategy is to run both analysis and select the better fitting one by model comparison. In model comparison, there are several criteria for assessing the goodness of a model, namely, the $R^{2}$, the Root Average Squared Error (RASE), and the Average Absolute Error (ASE). The $R^{2}$ is the variance explained whereas ASE is the average error rate of the model. RASE is the same as RMSE except that RMSE adjusts for degrees of freedom but RASE does not. The values in the final model (i.e. the validation model), instead of the training model, were evaluated because the training model is always overfitted. Unlike classical hypothesis testing, which relies on a cut-off for decision-making, the data mining method aims to recognize the data pattern without a rigid cut-off for variable selection.

After identifying the best model and the most important predictors, median smoothing was utilized to examine the relationship between the predictors and the learning outcomes. In this large-scale assessment, the sample size of each OECD member nation was around 5,000. When thousands of data points generate a noisy scatterplot, detecting a pattern within the sample becomes challenging. This problem, called overplotting, is resolved by dividing the data into several portions along the $\mathrm{x}$-dimension, computing the median of $\mathrm{y}$ in each portion, and looking at the trend after connecting the medians (Yu, 2014). 


\section{Results and Discussion}

\subsection{Hierarchical Cluster Analysis}

The constructs of readiness to learn, cultural engagement, political efficacy, and social trust were entered into a hierarchical cluster analysis. The grouping pattern displayed by the dendrogram (Figure 2) concurred with prior knowledge of history and culture. For example, it is unsurprising to see that Japan and Korea were grouped as a pair because these two East Asian cultures resemble each other in many aspects. In addition, the four North European countries were assigned into the same cluster: Denmark, Norway, Finland, and Sweden. The alignment between the preceding clustering results and the background knowledge supports the trustworthiness of other clustering results. In this analysis, the US, Canada, and New Zealand were grouped together, and therefore the subsequent analyses focused on comparing these three countries.

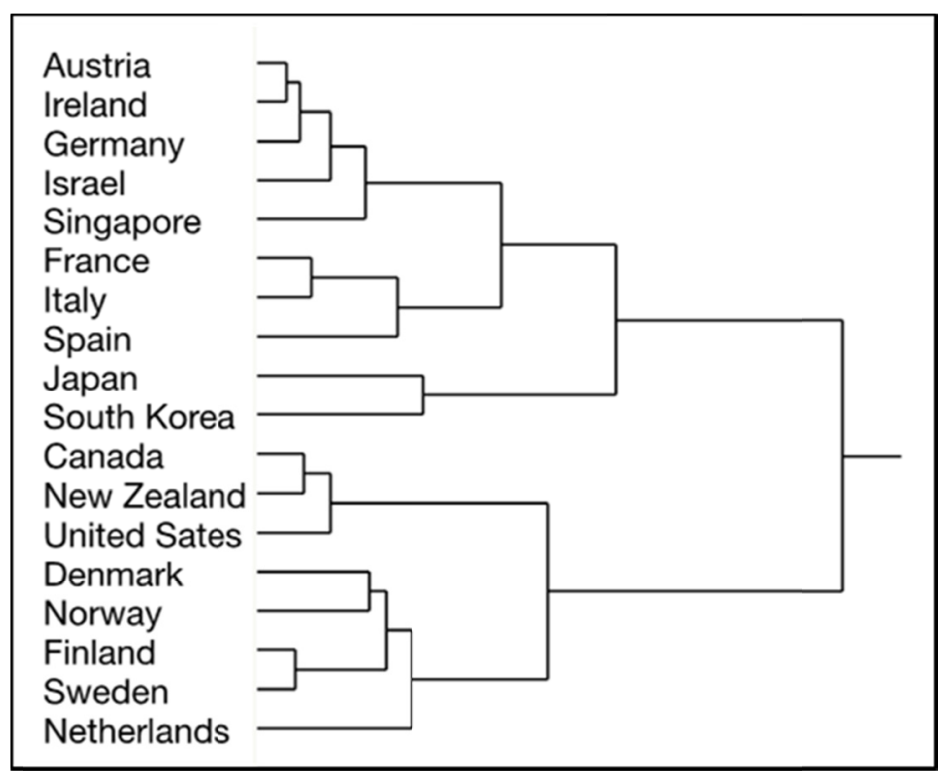

Figure 2. Dendrogram of 18 countries by readiness to learn, cultural engagement, political efficacy, and social trust

\subsection{Bagging, Boosting, and Model Comparison}

For each of these three countries, variables related to readiness to learn, cultural engagement, political efficacy, and social trust were input into bagging and boosting as predictors of composite learning outcomes, respectively. After model comparison, the better method, bagging or boosting, was retained (see Table 2). It is obvious that in training, the bootstrap method always yielded overfitted models because the R-square is unreasonably high. Therefore, all comparisons were based on the validation results only. Using the criteria of R-square, RASE, and AAE, the boosted tree models were adopted for the US and the New Zealand samples whereas the bagging model was considered the best for the Canadian sample. 
Table 2. Model comparison

\begin{tabular}{lcccccc}
\hline Country & Subset type & Ensemble method & $R^{2}$ & RASE & $A A E$ \\
\hline \multirow{4}{*}{ USA } & Training & Boosting & 0.2058 & 42.708 & 34.031 \\
& Training & Bagging & 0.4813 & 34.515 & 26.979 \\
& Validation & Boosting & $\mathbf{0 . 1 7 9 1}$ & 43.488 & 34.597 \\
& Validation & Bagging & 0.1685 & 43.768 & 34.689 \\
\hline \multirow{4}{*}{ Canada } & Training & Boosting & 0.1677 & 44.778 & 34.974 \\
& Training & Bagging & 0.3314 & 40.135 & 31.15 \\
& Validation & Boosting & 0.1526 & 45.86 & 35.727 \\
& Validation & Bagging & $\mathbf{0 . 1 6 3 8}$ & 45.556 & 35.554 \\
\hline \multirow{4}{*}{ New Zealand } & Training & Boosting & 0.1834 & 41.754 & 32.915 \\
& Training & Bagging & 0.4543 & 34.132 & 26.586 \\
& Validation & Boosting & $\mathbf{0 . 1 6 3 8 *}$ & 42.768 & 33.648 \\
& Validation & Bagging & 0.1459 & 43.222 & 33.983 \\
\hline
\end{tabular}

Note. The best model

Table 3 shows the ranking of predictors by the sum of squares (SS) in relation to the overall learning outcomes in the USA sample. The top three predictors were cultural engagement (voluntary work for non-profit organizations), social trust (other people take advantage of you), and readiness to learn (like learning new things). The bar on the right indicates the magnitude of SS. As shown by the length of the bar, after the third variable, SS substantively decreased.

Table 3. The final bootstrap forest model for the USA sample

\begin{tabular}{lll|l|}
\hline Variable & Sum of squares \\
\hline Voluntary work for non-profit organizations & $1.1594 \mathrm{e}+11$ \\
Other people take advantage of you & $8.5015 \mathrm{e}+10$ \\
Like learning new things & $7.687 \mathrm{e}+10$ & \\
Figure out how different ideas fit together & $4.5563 \mathrm{e}+10$ & \\
Get to the bottom of difficult things & $3.6352 \mathrm{e}+10$ & \\
No influence on the government & $3.2498 \mathrm{e}+10$ & \\
Looking for additional info & $1.7984 \mathrm{e}+10$ & & \\
Trust only few people & $1.5299 \mathrm{e}+10$ & & \\
\hline
\end{tabular}

Table 4 depicts the final bootstrap forest model for the Canadian sample. The number of splits in classifiers of bagging is much higher than that of boosting because bagging creates different models in parallel while boosting is an adaptive method. In the Canadian sample, the top three predictors of learning outcomes were the same as those found in the US, except in the Canada sample, the variable "like learning new things" ranked the second strongest factor while in the US, it ranked third.

Table 4. The final bootstrap forest model for the Canadian sample

\begin{tabular}{ll|l|}
\hline Variable & Sum of Square \\
\hline Voluntary work for non-profit organizations & 1772823817 \\
Like learning new things & 1691186037 \\
Other people take advantage of you & 1597977164 & \\
Get to the bottom of difficult things & 1538930661 & \\
No influence on the government & 1525696937 & \\
Figure out how different ideas fit together & 1308133190 & \\
Looking for additional info & 1211983219 & \\
Trust only a few people & 1161671094 & \\
\hline
\end{tabular}

Table 5 lists the ranking of predictors in boosting for the New Zealand sample. Unlike their American and Canadian peers, social trust (other people take advantage of you) was the most important predictor of learning 
outcomes while readiness to learn (Get to the bottom of difficult things, looking for additional info, and like learning new things) was less important than social trust.

Table 5. The final boosted tree model for the New Zealand sample

\begin{tabular}{lll|l|l|}
\hline Variable & Sum of Square \\
\hline Other people take advantage of you & 1228725821 \\
Get to the bottom of difficult things & 932036134 & \\
Looking for additional info & 810724351 & \\
Like learning new things & 601186913 & \\
No influence on the government & 442070283 & \\
Voluntary work for non-profit organizations & 370806044 & \\
Figure out how different ideas fit together & 368723070 & & \\
Trust only a few people & 336421345 & & \\
\hline
\end{tabular}

In all three countries, the relationship between readiness to learn and learning outcomes were positive and linear. However, non-linear patterns were detected when social trust and cultural engagement regressed against learning outcomes. Because the sample size was considerably large, median smoothing was employed for each level of the $\mathrm{X}$ variable. By doing so, the X-Y association could be detected by the trend of the medians. Illustrations from Figure 3-5 were based on the US sample. The Canadian graphs were not shown here because they were similar to the US results. Additionally, these relationships were consistent across males and females in all three countries. More graphs will be available upon request.

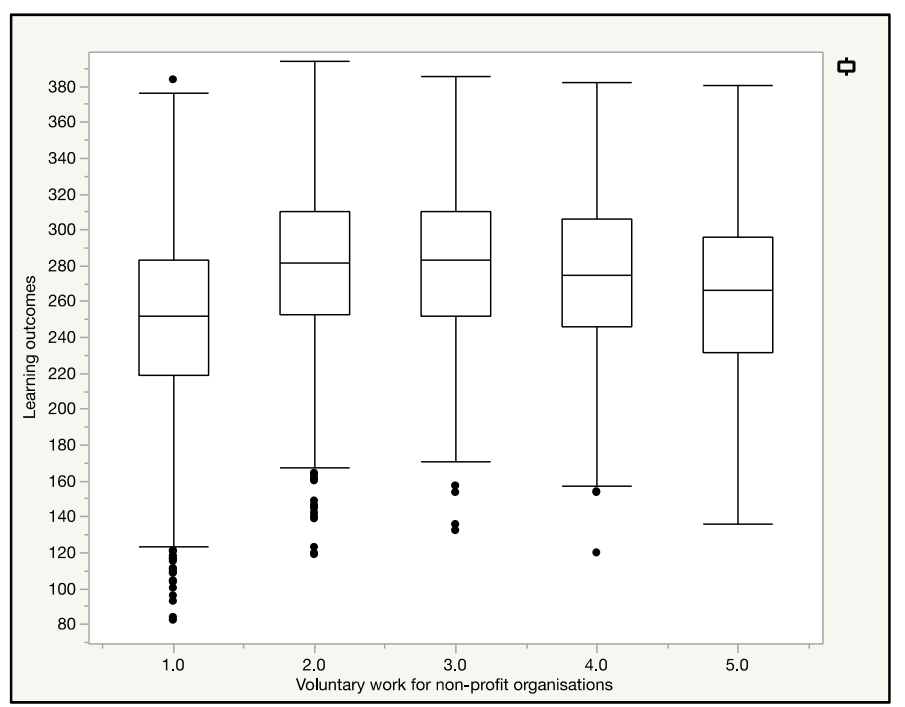

Figure 3. Median smoothing plot of learning outcomes and cultural engagement in the US sample 


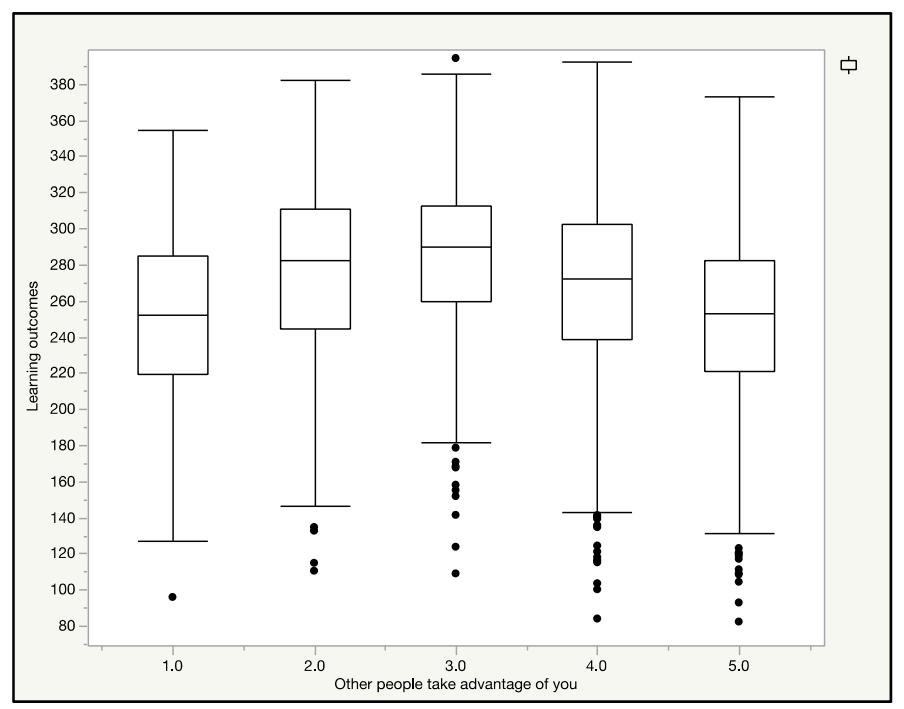

Figure 4. Median smoothing plot of learning outcomes and social trust in the US sample

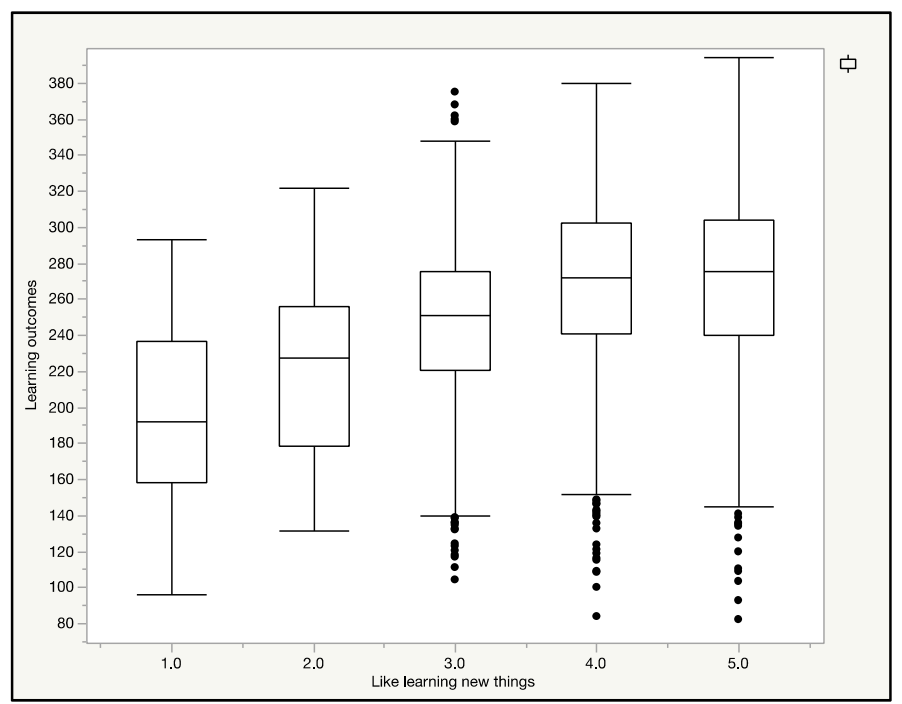

Figure 5. Median smoothing plot of learning outcomes and readiness to learn in the US sample

Figure 6-8 demonstrate the relationship between learning outcomes and the top three predictors in the New Zealand sample. Interestingly, although both "get to the bottom of difficult things" and "look for additional information" are positive when relating to learning outcomes, their benefits are flattened when the rating of these RtL variables approaches 5 . 


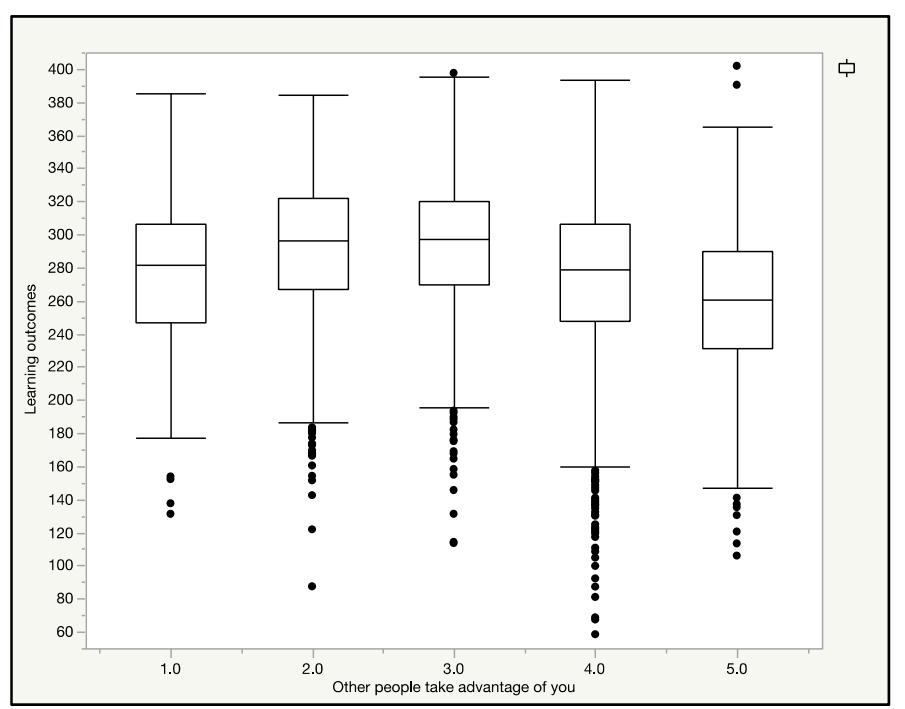

Figure 6. Median smoothing plot of learning outcomes and social trust in the New Zealand sample

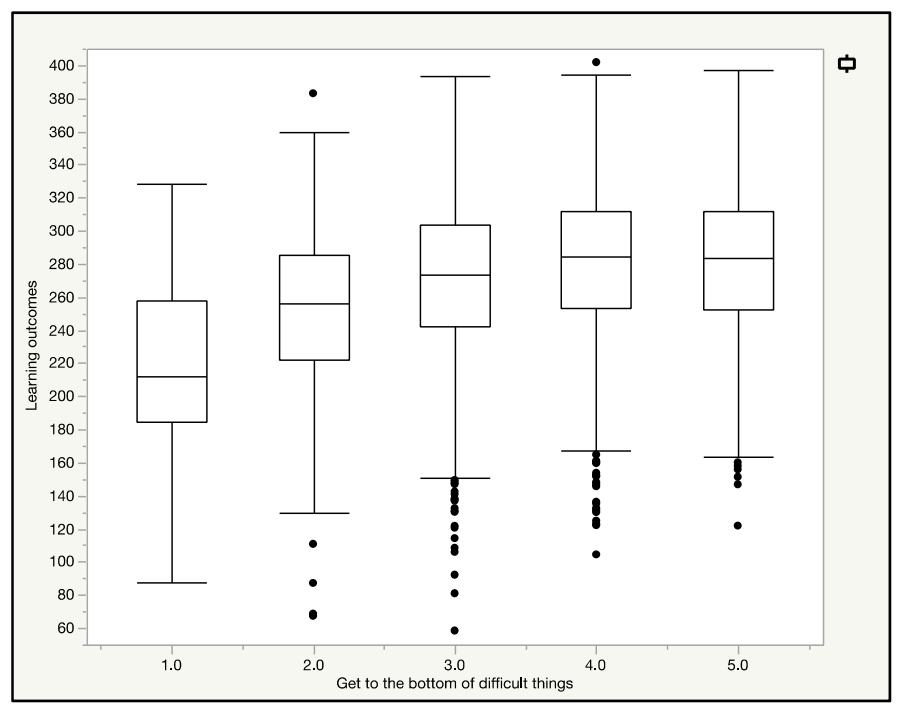

Figure 7. Median smoothing plot of learning outcomes and "get to the bottom of difficult things" in the New Zealand sample 


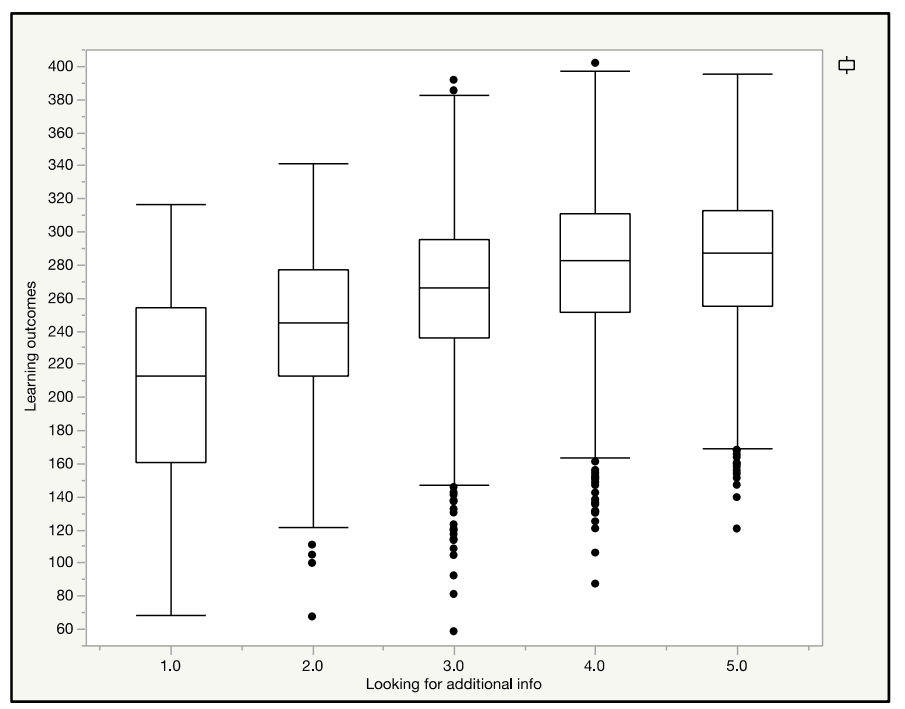

Figure 8. Median smoothing plot of learning outcomes and "Looking for additional information" in the New Zealand sample

\section{Implications and Recommendations}

The PIAAC data indicated three constructs to be the strongest predictors of test performances in the samples from the US, Canada, and New Zealand: cultural engagement, readiness to learn, and social trust.

\subsection{Readiness to Learn}

As predicted, one's motivation for learning correlated with goal-directed actions within a variety of behavioral domains, including academic and work performance. Among four questionnaires in the modified version of the Readiness to Learn (Rtl) scale, three items emerged as strong predictors of skill performances. As seen in Table 3 and 4, the variable "I like learning new things" was found to be the third strongest predictor in the US sample and the second strongest predictor in the Canadian sample. A strong agreement to this statement correlated with both higher composite and individual scores on literacy, numeracy, and problem-solving skills.

These results coincide with the recent investigation of Smith et al. (2015) who reported the RtL scale predicting all three assessed skills in the US sample. In the New Zealand sample, "I like to get to the bottom of difficult things" ranked as the second and "If I don't understand something, I look for additional information to make it clearer" was the third. Hence, the higher quantities of RtL items found in the New Zealand sample as compared to the US or Canadian sample is significant upon recognizing the higher performance of New Zealand. Particularly in numeracy scores, New Zealand not only outperformed the US and Canada, but it topped all OECD nations. This implies that motivation seems to be a crucial factor related to learning and task performance.

\subsection{Political Efficacy}

The construct of political efficacy did not arise as a crucial predictor of learning outcomes. In the bootstrap analysis report, it ranked fifth in Canada and New Zealand, and sixth in the US sample. Previous reports have indicated a relationship between high political efficacy and higher scores in PIAAC skill assessments (da Costa et al., 2014; OECD, 2013a). This current study suggests a less powerful influence of political efficacy on composite scores compared to constructs of social trust and of readiness to learn. It is possible that this result is related to the study of da Costa et al. (2014), which noted the wide variation in the political efficacy dimension across countries. Such a variation seems to be the case with the samples of the US, Canada, and New Zealand.

\subsection{Cultural Engagement}

Since learning outcomes and cultural engagement were related in both the US and Canadian samples, it suggests there is a commonality within these cultures that, either directly or indirectly, strengthens literacy, numeracy, and problem-solving. Prior research supported that participating in volunteer activities has positive effects on one's life (Wilson, 2000). It could be that the cultures in these two countries have similar expectations for literacy and knowledge. Gedvilienè, Staniulevičienè, and Gridel (2013) suggest that "living in a society where knowledge has high value forces citizens to learn how to deal with knowledge. That means they have to know how to transform material knowledge into reflexive knowledge in a constructivist manner" (p. 88). In other words, because 
knowledge is an important factor to a society, the society itself will require that an individual become more knowledgeable in order to participate. This creates a cycle of material knowledge of facts and measures with the reflexive knowledge that uses critical thinking and reflection. Cultural engagement through volunteering applies both aspects of this knowledge. Those who participate in volunteering must be adept in general knowledge and skills required to volunteer, as well as possess the abilities to reflect on and apply that general knowledge. It is important to note that cultural engagement and learning outcomes have a curvilinear relationship. One plausible explanation is that without volunteering in the community, one has fewer opportunities to broaden one's perspective of the world, resulting in a limited learning experience. However, spending too much time in volunteering services could also disrupt one's regular learning schedule.

\subsection{Social Trust}

The Pew Research Center found that issues of crime and corruption are strongly correlated with social trust (Wike \& Holzwart, 2008). Since New Zealand was rated as one of the most peaceful and least corrupt countries in the world, it is apparent this sense of safety is more likely to be promoted within the nation and among its citizens (New Zealand Now, 2016). This is consistent with the patterns observed in this study, which social trust is rated as the strongest predictor of learning outcomes within New Zealand, where people feel free and safe to be open and exchange knowledge.

As mentioned above, the process of learning requires one to rely on the information given by others. However, it is important to recognize that not all information is accurate or reliable. The ability to doubt is necessary for learning. The approach of a critical stance is defined as the evaluation of information "that involves the ability to weigh multiple pieces of information in order to determine the truth value of encountered claims, being prepared to doubt if necessary" (Mills, 2013, p. 404). Such an idea provides useful insight into the finding of non-linear patterns detected in the relationship between learning outcomes and social trust. If one simply accepts all information from others without engaging in critical thinking, this individual is likely to be misinformed. However, having too many doubts will also result in the isolation of knowledge and indecision. Thus, having the ability to trust and learn, but also be skeptical at times is most likely to maximize learning outcomes.

\section{Conclusion}

Using archival data from PIAAC, a global adult skills assessment, this study sought to contribute to the literature assessing the US adult skills and learning outcomes as it relates to countries of similar cultures. PIAAC and other international skills assessments are used by countries for insight into policy changes as well as the countries international status regarding human capital. While these assessments are accused of being too economically driven, the authors of this paper distinguished between the different purposes of the human capital and humanistic approaches which leaves room for the human capital approach to still be relevant for studies like this. Further, the data that can be offered to countries regarding their status in a global assessment is unsurpassable. It brings light to the path the global economy is headed in skilled labor and it prepares countries for the unemployment of their low-skilled laborers. In PIAAC, this is identified by testing three skill domains: literacy, numeracy, and technology-based problem-solving. In order to identify cultural traits that most impact learning outcomes, this study analyzed factors in PIAAC that relate to learning outcomes, including readiness to learn, cultural engagement, political efficacy, and social trust. These understood to be influenced by culture, as well as potentially relating to one's readiness to learn.

A hierarchical cluster analysis of culturally relevant variables from PIAAC, namely, patterns of learning behaviors, attitudes toward social trust, cultural engagement, and political efficacy, showed that culturally similar countries to the US were Canada and New Zealand. Using model comparison and big data analytical methods to determine the best model, three variables were discovered as strong predictors of learning outcomes: cultural engagement, readiness to learn, and social trust. The results of this study will contribute to the understanding of the global economy as it relates to human capital in countries with a similar history and culture as the US, Canada, and New Zealand, informing policy making that is interested in increasing learning outcomes.

This analysis is based on self-report data, meaning that the respondents might not provide the PIAAC researchers with highly accurate reports due to social desirability, transience, absent-mindedness, blocking memory, misattribution, suggestibility, bias, and other reasons (Loftus, 2016; Schacter, 1999; Seth Stephens-Davidowitz, 2017). Further, this analysis utilizes quantitative data without a qualitative context. In future studies, a mixed-method approach will be considered.

\section{References}

Abrams, L. C., Cross, R., Lesser, E., \& Levin, D. Z. (2003). Nurturing interpersonal trust in knowledge-sharing 
networks. Academy of Management Executive, 17(4), 64-77. https://doi.org/10.5465/ame.2003.11851845

Aktaş, M. (2012). Cultural values and learning styles: A theoretical framework and implications for management development. Procedia-Social and Behavioral Sciences, 41, 357-362. https://doi.org/10.1016/j.sbspro.2012.04.041

Ananiadou, K., \& Claro, M. (2009). Twenty-first century skills and competences for new millennium learners in OECD countries. OECD Education Working Papers, 41. https://doi.org/10.1787/218525261154

Anderson, M. R. (2010). Community psychology, political efficacy, and trust. Political Psychology, 31(1), 59-84. https://doi.org/10.1111/j.1467-9221.2009.00734.x

Bagley, S. S., \& Portnoi, L. M. (2014). Setting the stage: Global competition in higher education. New Directions for Higher Education, 168, 5-11. https://doi.org/10.1002/he.20109

Borum, R. (2010). The science of interpersonal trust. Mental Health Law and Policy Faculty Publications. Retrieved from http://scholarcommons.usf.edu/mhlp_facpub/574

Bowler, S., \& Donovan, T. (2002). Democracy, institutions and attitudes about citizen influence on government. British Journal of Political Science, 32, 371-390. https://doi.org/10.1017/s0007123402000157

Brady, H. E., Verba, S., \& Schlozman, K. L. (1995). Beyond SES: A resource model of political participation. American Political Science Review, 89, 271-294. https://doi.org/10.2307/2082425

Brown, P., Green, A., \& Lauder, H. (2001). High skills: Globalization, competitiveness, and skill formation: globalization, competitiveness, and skill formation. Oxford: Oxford University Press.

Cerasoli, C. P., Nicklin, J. M., \& Ford, M. T. (2014). Intrinsic motivation and extrinsic incentives jointly predict performance: A 40-year meta-analysis. Psychological Bulletin, 140, 980-1008. https://doi.org/10.1037/a0035661

Crotty, J. M. (2015). Thirty-six million Americans lack basic work skills. Forbes. Retrieved from http://www.forbes.com/sites/jamesmarshallcrotty/2015/02/28/a-staggering-36-million-americans-lack-basic -work-skills/\#ced30d319af8

Da Costa, P. D., Rodrigues, M., Vera-Toscano, E., \& Weber, A. (2014). Education, adult skills, and social outcomes. JRC Science and Policy Reports. https://doi.org/10.1111/ejed.12211

De Vita, G. (2001). Learning styles, culture and inclusive instruction in the multicultural classroom: A business and management perspective. Innovations in Education and Teaching International, 38(2), 165-174. https://doi.org/10.1080/14703290110035437

Dietterich, T. G. (2000). An experimental comparison of three methods for constructing ensembles of decision trees: Bagging, boosting and randomization. Machine Learning, 40(2), 139-157. https://doi.org/10.1023/A:1007607513941

Furedi, F. (2013, December). The PISA global league table overlooks cultural factors that incentivize learning: It is cultural norms in communities that orient children towards education. Independent. Retrieved from http://www.independent.co.uk/voices/comment/the-pisa-global-league-table-overlooks-cultural-factors-thatincentivize-learning-8982654.html

Gedvilienė, G., Staniulevičienė, D., \& Gridel, C. (2013). Strengthening social cohesion: Adult learning through the practice of volunteering. Social Education, 1, 86-97.

Gonzales, A., Jones, D., \& Ruiz, A. (2014). Toward achievement in the "Knowledge Economy" of the 21st Century: Preparing students through T-STEM academies. Research in Higher Education Journal, 25(1), 1-14. Retrieved from http://www.aabri.com/manuscripts/141935.pdf

Gorges, J., Maehler, D. B., Koch, T., \& Offerhaus, J. (2016). Who likes to learn new things: measuring adult motivation to learn with PIAAC data from 21 countries. Large-scale Assessments in Education, 4(9), 1-22. https://doi.org/10.1186/s40536-016-0024-4

Hanushek, E. A., Schwerdt, G., Wiederhold, S., \& Woessmann, L. (2013). Return to skills around the world: Evidence from PIAAC. Institution for the Study of Labor. https://doi.org/10.3386/w19762

Hayes, B., \& Bean, C. S. (1993). Political efficacy: A comparative study of the United States, West Germany, Great Britain, and Australia. European Journal of Political Research, 23(3), 261-280. https://doi.org/10.1111/j.1475-6765.1993.tb00359.x

Heckman, J. J., \& Kautz, T. (2013). Fostering and measuring skills: Interventions that improve character and 
cognition. National Bureau of Economic Research. https://doi.org/10.3386/w19656

Held, D., \& McGrew, A. (2007). Globalization/anti-globalization: Beyond the great divide (2nd ed.). London, UK: Polity Press.

Holtbrügge, D., \& Mohr, A. T. (2010). Cultural determinants of learning style preferences. Academy of Management Learning \& Education, 9, 622-637. https://doi.org/10.5465/amle.9.4.zqr622

Joy, S., \& Kolb, D. A. (2009). Are there cultural differences in learning style? International Journal of Intercultural Relations, 33(1), 69-85. https://doi.org/10.1016/j.ijintrel.2008.11.002

Kusurkar, R. A., Ten Cate, T. J., Vos, C. M. P., Westers, P., \& Croiset, G. (2013). How motivation affects academic performance: A structural equation modelling analysis. Advances in Health Sciences Education, 18(1), 57-69. https://doi.org/10.1007/s10459-012-9354-3

Linton, J. (2010). United States Department of Education Update. Journal of Correctional Education, 61(1), 6-8.

Loftus, E. (2016, April). The fiction of memory. Paper presented at the Western Psychological Association Convention. Long Beach, CA.

Meir, R., \& Rätsch, G. (2003). An introduction to boosting and leveraging. In: Advanced Lectures on Machine Learning. Lecture Notes in Computer Science, 2600, 118-183. https://doi.org/10.1007/3-540-36434-x_4

Menon, R. (2000, Feb). On my mind: Should the United States emulate Singapore's education system to achieve Singapore's success in the TIMSS? Mathematics Teaching in the Middle School, 5(6), 345-347.

Meyerson, H. (2014). Technology and trade policy is pointing America toward a job apocalypse. Washington Post. Retrieved from https://www.washingtonpost.com/opinions/harold-meyerson-technology-and-tradepolicy-is-pointing-america-toward-a-job-apocalypse/2014/03/26/ba331784-b513-11e3-8cb6284052554d74_ story.html?tid=a_inl\&utm_term $=$. fe2da092721c

Mills, C. (2013). Knowing when to doubt: Developing a critical stance when learning from others. Developmental Psychology, 49, 404-418. https://doi.org/10.1037/a0029500

Moran, R. T., Abramson, N. R., \& Moran, S. V. (2014). Managing cultural differences. New York, NY: Routledge.

National Center for Education Statistics [NCES]. (2016). Program for the international assessment of adult competencies (PIAAC): Sample literacy items. OECD Publishing. Retrieved from https://nces.ed.gov/surveys/piaac/sample_lit.asp

New Zealand Now. (2016). Safe and security. New Zealand Immigration. Retrieved from https://www.newzealandnow.govt.nz/why-choose-nz/safe-secure

Optiz, D., \& Maclin, R. (1999). Popular ensemble methods: An empirical study. Journal of Artificial Intelligence Research, 11, 169-198. https://doi.org/10.1613/jair.614

Organization for Economic Co-operation and Development [OECD] (2016). Skills matter: Further results from the survey of adult skills. OECD Publishing. https://doi.org/10.1787/9789264258051-en

Organization for Economic Co-operation and Development [OECD]. (2012). Literacy, numeracy and problem solving in technology-rich environments framework for the OECD survey of Adult Skill. OECD Publishing. https://doi.org/10.1787/9789264128859-en

Organization for Economic Co-operation and Development [OECD]. (2013a). OECD skills outlook 2013: first results from the Survey of Adult Skills. OECD Publishing. https://doi.org/10.1787/9789264204256-sum-hu

Organization for Economic Co-operation and Development [OECD]. (2013b). Technical report of the survey of adult skills (PIAAC). OECD Publishing. https://doi.org/10.1787/9789264204027-8-en

Organization for Economic Co-operation and Development [OECD]. (2013c). The survey of adult skills: Reader's companion. OECD Publishing. https://doi.org/10.1787/9789264258075-en

Pasek, J., Feldman, L., Romer, D., \& Jamieson, K. H. (2008). Schools as incubators of democratic participation: Building long-term political efficacy with civic education. Applied Development Science, 12(1), 26-37. https://doi.org/10.1080/10888690801910526

Rattan, A., Savani, K., Naidu, N. V. R., \& Dweck, C. S. (2012). Can everyone become highly intelligent? Cultural differences in and societal consequences of beliefs about the universal potential for intelligence. Journal of Personality and Social Psychology, 103, 787-803. https://doi.org/10.1037/a0029263 
Ravitch, D. (2011, February). Keynote address. Speech presented at the Annual Meeting of the American Association of School Administrators, Denver, CO. Retrieved from http://www.aasa.org/uploadedFiles/ NCE/The_Conference_Daily_Online/2011_Conference_Daily/2011_Conference_Daily_Day_3_February_1 8,2011/DianeRavitchSpeech-NCE11-text-format.pdf

Rich, B. L., Lepine, J. A., \& Crawford, E. R. (2010). Job engagement: Antecedents and effects on job performance. Academy of Management Journal, 53, 617-635. https://doi.org/10.5465/amj.2010.51468988

Rudd, M. (2015). Awareness of humanities, arts and social science (HASS) research is related to patterns of citizens' community and cultural engagement. Social Sciences, 4, 313-338. https://doi.org/10.3390/socsci4020313

Schacter, D. L. (1999). The seven sins of memory: Insights from psychology and cognitive neuroscience. American Psychology, 54, 182-203. https://doi.org/10.1037/0003-066x.54.3.182

Smith, M. C., Rose, A. D., Ross-Gordon, J., \& Smith, T. J. (2015). Adults' readiness to learn as a predictor of literacy skills. Retrieved from https://static1.squarespace.com/static/51bb74b8e4b0139570ddf020/t/ 54da7802e4b08c6b90107b4f/1423603714198/Smith_Rose_Ross-Gordon_Smith_PIAAC.pdf

Stephens-Davidowitz, S. (2017). Everybody lies: Big data, new data, and what the Internet can tell us about who we really are. New York, NY: Dey Street Books. https://doi.org/10.7202/1044853ar

Sternberg, R. J., \& Grigorenko, E. L. (2004). Intelligence and culture: How culture shapes what intelligence means, and the implications for a science of well-being. Philosophical Transactions of the Royal Society B: Biological Sciences, 359, 1427-1434. https://doi.org/10.1098/rstb.2004.1514

Tsatsaroni, A., \& Evans, J. (2014). Adult numeracy and the totally pedagogised society: PIAAC and other international surveys in the context of global educational policy on lifelong learning. Educational Studies in Mathematics, 87(2), 167-186. https://doi.org/10.1007/s10649-013-9470-x

Vansteenkiste, M., Sierens, E., Soenens, B., Luyckx, K., \& Lens, W. (2009). Motivational profiles from a self-determination perspective: The quality of motivation matters. Journal of Educational Psychology, 101, 671-688. https://doi.org/10.1037/a0015083

Wike, R., \& Holzwart, K. (2008). Where trust is high, crime and corruption are low. Pew Research Center. Retrieved from http://www.pewglobal.org/2008/04/15/where-trust-is-high-crime-and-corruption-are-low/ \#fn-1036-2

Wilson, J. (2000). Volunteering. Annual Review of Sociology, 26, 215-240. https://doi.org/10.1146/annurev.soc.26.1.215

Wu, M. (2004). Plausible values. Rasch Measurement Transactions, 18, 976-978. Retrieved from https://www.rasch.org/rmt/rmt182c.htm

Wujek, B. (2016, September). Practical guidance for machine learning applications. Paper presented at SAS Analytics Experience Conference, Las Vegas, NV.

Yamazaki, Y. (2005). Learning styles and typologies of cultural differences: A theoretical and empirical comparison. International Journal of Intercultural Relations, 29, 521-548. https://doi.org/10.1016/j.ijintrel.2005.07.006

Yu, C. H. (2014). Dancing with the data: The art and science of data visualization. Saarbrucken, Germany: LAP.

Zakaria, F. (2014, May 1). America's educational failings. The Washington Post. Retrieved from https://www.washingtonpost.com/opinions/fareed-zakaria-americas-educational-failings/2014/05/01/b61 eaa 22-d15c-11e3-9e25-188ebe1fa93b_story.html?utm_term=.7be82e04f181

\section{Copyrights}

Copyright for this article is retained by the author(s), with first publication rights granted to the journal.

This is an open-access article distributed under the terms and conditions of the Creative Commons Attribution license (http://creativecommons.org/licenses/by/4.0/). 